\title{
Increasing Lutein Consumption - Are all Luteins Alike?
}

\author{
Samanta Maci
}

Senior Manager Europe, Scientific Affairs and Technical Services, Kemin Health Europe

\section{Abstract}

Epidemiological and intervention studies suggest that lutein may act as a nutritional factor able to modulate visual performance as well as the processes implicated in the pathogenesis and progression of degenerative eye diseases. Since lutein cannot be synthesised by the body, and daily dietary consumption is generally below the level of intake found to be beneficial in clinical studies, increased consumption - through diet or supplementation - is recommended. The prerequisites for lutein to benefit the eye are: release from the food or food supplement matrix in which it is included; absorption by the intestinal cell; presence in adequate concentrations in serum; and deposition of serum lutein into the macula of the eye. Not all lutein ingredients are alike so, when recommending eye supplements to patients, in addition to looking for safe products, it is critical to ensure that the lutein ingredient used is absorbed properly by the body and has proven its efficacy in clinical trials.
\end{abstract}

\section{Keywords}

Lutein, zeaxanthin, macular pigment, dietary sources, absorption, lutein supplementation, bioavailability

Disclosure: Samanta Maci is an employee of Kemin Health.

Received: 6 September 2011 Accepted: 1 October 2011 Citation: European Ophthalmic Review, 2011;5(2):127-9 DOI: 10.17925/EOR.2011.05.02.127 Correspondence: Samanta Maci, Senior Manager Europe, Scientific Affairs and Technical Services, Kemin Health Europe, Campo Grande, 35-8², 1700-087 Lisboa, Portugal. E: Samanta.Maci@kemin.com

Support: The publication of this article was funded by Kemin Health.

Growing scientific evidence supports the beneficial role of lutein in eye health. Lutein is found, together with its isomer zeaxanthin, in almost all the structures of the eye. Lutein and zeaxanthin are the only two dietary carotenoids selectively concentrated in the lens and in the macula, where they are the key components of the macular pigment (MP). An additional carotenoid present in the macula, meso-zeaxanthin, is a stereoisomer of lutein and zeaxanthin that is not naturally found in the human diet.

Epidemiological studies have shown that a daily intake of at least $6 \mathrm{mg}$ of lutein plus zeaxanthin from dietary sources may decrease the risk of developing advanced age-related macular degeneration (AMD), ${ }^{1}$ the incidence of cataract $^{2}$ and the need for cataract extraction. ${ }^{3,4}$ In studies using higher doses of lutein, administered alone or together with other antioxidants in a supplement form, the interventions were effective in increasing the macular pigment optical density (MPOD) in AMD patients and improving visual function in subjects suffering from AMD or cataract. ${ }^{5,6}$ These findings suggest that lutein and zeaxanthin may act as nutritional factors capable of modulating the processes implicated in the pathogenesis and progression of these degenerative eye diseases. Evidence of the beneficial effects of long-term supplementation with $10 \mathrm{mg}$ lutein plus $2 \mathrm{mg}$ zeaxanthin on the progression of advanced $A M D$, cataract and moderate vision loss is currently being investigated in the Age-related eye disease study 2 (AREDS2), a large-scale clinical trial conducted by the National Eye Institute of the US National Institutes of Health whose results are expected by 2013.?

The effects of lutein supplementation have also been explored in clinical trials conducted in patients with retinitis pigmentosa. They showed the ability of lutein to increase MPOD ${ }^{8,9}$ and slow the decline in the loss of visual field.., 10

In recent years, research interest has focused on the relationship between high daily intakes of lutein and zeaxanthin and the improvement in visual performance in healthy young adults. Observational studies have clearly shown that individuals with a higher density of MP are able to tolerate a higher intensity of glaring light and have significantly shorter photostress recovery times. ${ }^{11}$ These findings were strengthened by the results of an intervention study published in 2008, which showed that increasing MPOD through six months of supplementation with $10 \mathrm{mg}$ lutein plus $2 \mathrm{mg}$ zeaxanthin improved glare tolerance and reduced photostress recovery time. ${ }^{12}$

The benefits associated with lutein and zeaxanthin intake (and high MP density) are ascribed to particular characteristics of these carotenoids, which are:

- the antioxidant activity, leading to a reduction of oxidative damage caused by reactive oxygen species and free radicals, which is especially important in the retina, a tissue that is particularly susceptible to oxidative stress; and

- the ability to filter short wavelengths of visible light, associated with visual performance effects. ${ }^{13}$

\section{Dietary Sources and Intakes}

Like all the other carotenoids, lutein and zeaxanthin are not synthesised by humans. Their presence and concentration in serum 
Figure 1: Lutein and Zeaxanthin Content of Selected Foods

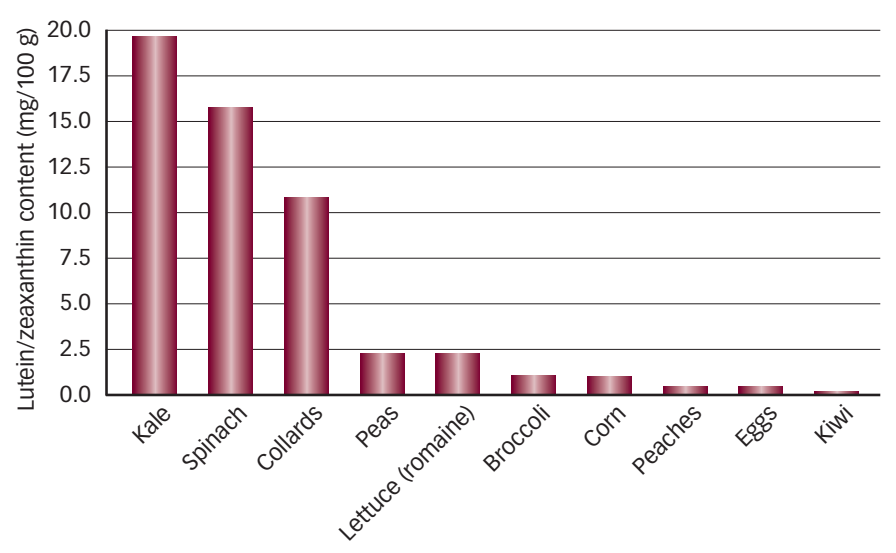

Source: USDA National Nutrient Database for Standard Reference, Release 23, 2010."

and in the eye are entirely of dietary origin and can be raised by increasing intake, via diet and/or supplementation. Meso-zeaxanthin, however, is not obtained from the diet, nor is it found in serum, and has been shown to be formed through lutein metabolism, apparently exclusively within the macula. ${ }^{14}$

The richest source of lutein and zeaxanthin in the human diet is green leafy vegetables (such as kale, spinach and collards), corn and corn products and eggs - which are one of the most bioavailable sources of lutein and zeaxanthin due to the lack of lutein-matrix interaction observed in plants and the high lipid and cholesterol content of the yolk ${ }^{15}$ (see Figure 1). Most values for lutein and zeaxanthin are reported as total sum; however, green leafy vegetables contain very small or no amounts of zeaxanthin. ${ }^{16,17}$

Lutein and zeaxanthin exist in nature in two different chemical forms: the unesterified or 'free' form - such as in green leafy vegetables - and the esterified form - in which a fatty acid is attached to the hydroxyl groups at each end of the lutein (and zeaxanthin) molecule. The latter form is usually found in flowers and in very small amounts in yellow-orange vegetables and fruits. The human diet is predominantly composed of lutein in the free form and this is the only form that circulates in the serum and is deposited in the eye regardless of the type of lutein ingested..$^{18,19}$

A diet rich in vegetables and fruits normally supplies an adequate level of lutein per day. However, the daily consumption of lutein and zeaxanthin in Western countries is generally modest, averaging only between 1 and $2.5 \mathrm{mg} /$ day in the $\mathrm{US}^{20}$ and between 1.56 and $3.25 \mathrm{mg} /$ day in Europe depending on the country. ${ }^{21}$ These amounts are well below the level of intake that is thought to be beneficial for eye health. Commercial ingredients containing lutein and zeaxanthin are on the market to increase the intake for people who are not ingesting sufficient quantities of these xanthophylls through their diet.

\section{Lutein Absorption}

Lutein is one of the six major carotenoids found in human blood The presence of lutein in the blood varies considerably between individuals and may be influenced by external and host factors that can interfere with the different steps involved in its absorption: source of lutein ingested, duration of lutein intake, amount of fat in the diet, concomitant ingestion of fibres, nutritional status, genetic factors and age of the individual. ${ }^{22}$
To be deposited in the eye and thus provide its health benefits, Iutein has to be absorbed by the body and circulated through the serum. Lutein is a lipophilic molecule and its absorption follows the same processes as other fat-soluble dietary compounds such as dietary lipids or vitamin E. Thus, the concomitant ingestion of some fat is necessary for its optimal absorption. Generally, after release from the food matrix into which the lutein is ingested and release into the lumen of the intestine, the lutein molecules are incorporated into mixed micelles formed from the dietary fats and bile acids present. Lutein is then absorbed by the mucosa of the small intestine via passive diffusion, incorporated into chylomicrons and transported via the lymphatic system to the liver. Finally, in the hepatocytes, lutein is incorporated into low-density and high-density lipoproteins and transported to target tissues. ${ }^{23}$ In the retina, a specific lutein-binding protein mediates the selective uptake of this carotenoid. ${ }^{24}$

One of the most critical factors influencing lutein absorption is the source of lutein ingested: its chemical form and the matrix in which the lutein is included. The nature of the source is of particular importance when increased lutein intake is obtained through supplementation.

\section{Increase Bioavailability with FloraGLO ${ }^{\circledR}$ Lutein}

FloraGLO Lutein (Kemin Health) is the leading lutein ingredient brand worldwide and is intended for inclusion in either dietary supplements, foods or beverages to increase the intake of lutein and zeaxanthin. It provides the same non-esterified form of lutein and zeaxanthin that is naturally found in vegetables. A pharmacokinetic study conducted in healthy volunteers has clearly demonstrated that the lutein from FloraGLO Lutein is absorbed unmodified by the body and circulates in the bloodstream..$^{25}$ Intervention studies have confirmed the efficacy of supplementation with this patented ingredient to increase MPOD and improve visual performance in AMD patients and healthy subjects., ${ }^{5,12}$ The investigators of the AREDS2 chose FloraGLO Lutein as the source of lutein to be assessed in this important clinical trial.

Intake of supplements containing FloraGLO Lutein has been shown to increase serum lutein more than a similar dose of free lutein from green vegetables. ${ }^{26,27}$

Another topic of discussion in the scientific community deals with the possible differences in absorption of free lutein as compared to the esterified compound. Because only the free form is absorbed by the body, the fatty acids attached to the esterified form must be removed before absorption. Because this action, performed by gut enzymes not yet fully identified, does not seem to be $100 \%$ efficient, ${ }^{28,29}$ there is reason to believe that lutein esters are less bioavailable than free lutein. Two small studies conducted to compare the absorption of lutein and lutein esters concluded that esterification does not impair lutein absorption; however, certain aspects of the design of these studies (including the amount of fat administered, duration of supplementation, product formulations and/or dose) do not allow clear conclusions to be drawn on this topic. ${ }^{15,30}$

A recently published intervention study provided a better understanding of the absorption of the different forms of lutein by comparing the serum lutein response resulting from 28 days of supplementation with FloraGLO Lutein with the response resulting from lutein esters provided in identical doses, galenic form and similar conditions. ${ }^{31}$ 
This randomised, double-blind parallel clinical trial, conducted with 72 healthy male and females volunteers, clearly confirmed the greater bioavailability of free lutein. Although both supplements increased serum lutein levels compared with baseline levels, supplementation with FloraGLO Lutein resulted in a statistically significant greater percentage increase in serum lutein levels $(p=0.0054)$, a greater absolute (baseline subtracted) change in the serum lutein levels per $\mathrm{mg}$ of lutein dose administered ( $p=0.0011$ at day 28) and a greater amount of lutein in the bloodstream as measured by serum lutein area under the curve $\left(\mathrm{AUC}_{(0-28 d)}\right)(\mathrm{p}=0.0187)$ (see Figure 2). Additionally, no lutein esters were detectable in the bloodstream.

Lutein in its crystalline form is very sensitive to oxidation, heat and humidity, therefore it is important to encapsulate it in a matrix to provide protection. The formulation technology used by the ingredient manufacturer for that purpose must ensure that:

- the materials used are suitable for human consumption;

- the ingredient can resist further processing (for example, inclusion in eye supplement tablets) so that the dose of lutein on the label is stable throughout the product's shelf life; and

- the lutein is released from the encapsulation matrix in the gut; this is of outmost importance, since it is a requirement for the lutein to be absorbed by the body.

A recent randomised, double-blind, cross-over study explored this critical point by comparing the bioavailability of two commercially available free lutein ingredients that differed in matrix characteristics: FloraGLO Lutein, which is microencapsulated in a starch matrix (Actilease $^{\mathrm{TM}}$ technology, DSM Nutritional Products), and a free lutein incorporated into an alginate matrix. The study results, presented at the European Association for Vision and Eye Research conference in 2010,33 confirmed that not all lutein encapsulation forms are alike: the increase in lutein plasma AUC was 10 times higher following the single dose

\section{Figure 2: $A_{U C} C_{(0-28 d)}$ Values Comparison Between the Free Lutein and Lutein Esters Groups}

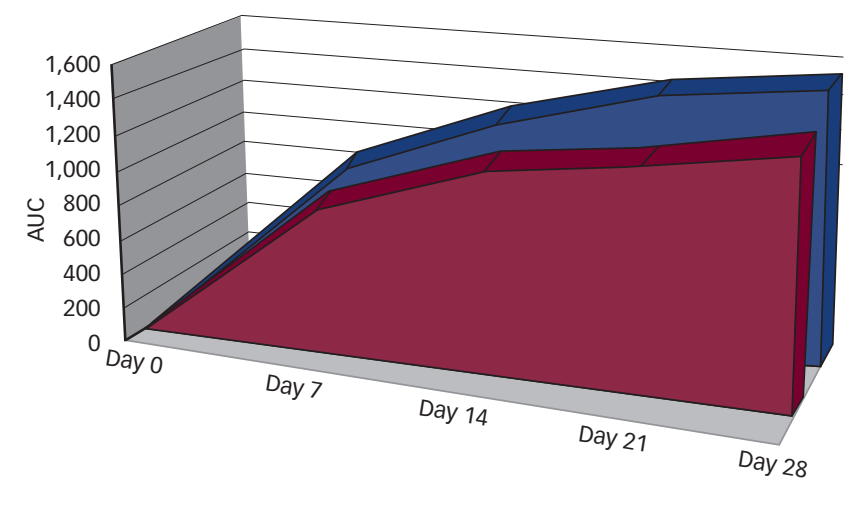

Lutein esters group

Free lutein group

AUC $=$ area under the curve. Source: Norkus, 2011. ${ }^{32}$ Reproduced with author's permission

administration of $20 \mathrm{mg}$ of FloraGLO Lutein compared with the same dose of free lutein incorporated into an alginate matrix.

\section{Conclusions}

The antioxidants and blue-light filtering properties of lutein, together with its selective accumulation in the retina, support its beneficial effects in eye health. Although no dietary reference has yet been set for lutein, data on beneficial effects observed in intervention trials support the daily intake of $10 \mathrm{mg}$ of lutein, a dose that has been recognised to be safe..$^{34,35}$ Since this carotenoid is not synthesised by the body and daily dietary consumption is generally low, increased consumption of lutein is recommended. Not all lutein ingredients are alike so, when recommending eye supplements to patients, in addition to looking for safe products, it is critical to ensure that the lutein ingredient used is absorbed properly by the body and has proven its efficacy in clinical trials.
1. Seddon JM, Ajani UA, Sperduto RD, et al., Dietary carotenoids, vitamins $A, C$, and E, and advanced age-related macular degeneration. Eye Disease Case-Control Study Group, JAMA 1994;272(18):1413-20

2. Christen WG, Liu S, Glynn RJ, et al., Dietary carotenoids, vitamin $\mathrm{C}$ and $\mathrm{E}$, and risk of cataract in women: a vitamin $C$ and $E$, and risk of cataract in women: a
prospective study, Arch Ophthalmol, 2008:126(1):102-9.

3. Chasan-Taber L, Willett WC, Seddon JM, et al., A prospective study of carotenoid and vitamin A intakes and risk of catarac extraction in US women, Am I Clin Nutr, 1999;70(4):509-16.

4. Brown L, Rimm EB, Seddon JM, et al., A prospective study of carotenoid intake and risk of cataract extraction in US men, Am I Clin Nutr, 1999;70(4):517-24.

5. Richer S, Stiles W, Statkute L, et al., Double-masked, placebocontrolled, randomized trial of lutein and antioxidant supplementation in the intervention of atrophic age-related macular degeneration: the Veterans LAST study (Lutein macular degeneration. the veterans LAST study (Lutein

6. Olmedilla B, Granado F, Blanco I, Vaquero M, Lutein, but not alpha-tocopherol, supplementation improves visual function in patients with age-related cataracts: a 2-y double-blind, placebo-controlled pilot study, Nutrition, 2003;19(1):21-4.

Age-Related Eye Disease Study 2 (AREDS2) website. Available at: www.emmes.com/study/areds2 (accessed 20 September 2011).

8. Aleman TS, Duncan UL, Bieber ML, et al., Macular pigment and lutein supplementation in retinitis pigmentosa and Usher syndrome, Invest Ophthalmol Vis Sci, 2001;42(8):1873-81.

Berson EL, Rosner B, Sandberg MA, et al., Clinical trial Berson EL, Rosner B, Sandberg MA, et al., Clinical trial
of lutein in patients with retinitis pigmentosa receiving vitamin A, Arch Ophthalmol, 2010;128(4):403-11.

10. Dagnelie G, Zorge IS, MCDonald TM, Lutein improves visual function in some patients with retinal degeneration: a pilo study via the Internet, Optometry, 2000;71(3):147-64.

11. Stringham JM, Hammond BR Jr., The glare hypothesis of macular pigment function, Optom Vis Sci, 2007:84(9):859-64.

12. Stringham JM, Hammond BR, Macular pigment and visual performance under glare conditions, Optom Vis Sci, 2008:85(2):82-8.

13. Wooten BR, Hammond BR, Macular pigment: influences on visual acuity and visibility, Prog Retin Eye Res, 2002;21(2):225-40.
14. Johnson EJ, Neuringer M, Russell RM, et al., Nutritional manipulation of primate retinas, III: Effects of lutein or zeaxanthin supplementation on adipose tissue and retina of xanthophyllfree monkeys, Invest Ophthalmol Vis Sci, 2005;46(2):692-702.

15. Chung HY, Rasmussen HM, Johnson EJ, Lutein bioavailability is higher from lutein-enriched eggs than from supplements is higher from lutein-enriched eggs than from suppling
and spinach in men, J Nutr, 2004:134(8):1887-93.

16. Perry A, Rasmussen $\mathrm{H}$, Johnson EJ, Xanthophyll (lutein, zeaxanthin) content in fruits, vegetables and corn and egg products, J Food Compost Anal, 2009;22:9-15.

17. US Department of Agriculture, Agricultural Research Service USDA National Nutrient Database for Standard Reference, Release 23, 2010. Available at: www.ars.usda.gov /SP2UserFiles/Place/12354500/Data/SR23/nutrlist/sr23w338 .pdf (accessed 20 September 2011).

18. US Department of Agriculture, Agricultural Research Service, USDA-NCC Carotenoid Database for U. S. Foods, 1998. Available at: www.nal.usda.gov/fnic/foodcomp/Data/car98 /car_tble.pdf (accessed 20 September 2011).

19. Bone RA, Landrum JT, Tarsis SL, Preliminary identification of the human macular pigment, Vision Res, 1985;25(11):1531-5.

20. Centers for Disease Control and Prevention, National Center for Health Statistics. National Health and Nutrition Examination Survey Data 2001-2002. Available at: www.cdc .gov/nchs/nhanes/nhanes2001-2002/nhanes01_02.htm (accessed 20 September 2011)

21. O'Neill ME, Carroll Y, Corridan B, et al., A European carotenoid database to assess carotenoid intakes and its use in a fivecountry comparative study, Br I Nutr, 2001;85(4):499-507.

22. Van het Hof KH, West CE, Weststrate JA, Hautvast JG, Dietary factors that affect the bioavailability of carotenoids, I Nutr, 2000;130(3):503-6.

23. Stahl W, van den Berg H, Arthur J, et al., Bioavailability and metabolism, Mol Aspects Med, 2002;23(1-3):39-100.

24. Li B, Vachali P, Frederick JM, Berstein PS, Identification of StARD3 as a lutein-binding protein in the macula of the primate retina, Biochemistry, 2011:50(13):2541-9.

25. Thürmann PA, Schalch W, Aebischer JC, et al., Plasma kinetics of lutein, zeaxanthin, and 3-dehydro-lutein after multiple oral doses of a lutein supplement, Am I Clin Nutr,
2005;82(1):88-97

26. Castenmiller JJ, West CE, Linssen JP, et al., The food matrix of spinach is a limiting factor in determining the bioavailability of beta-carotene and to a lesser extent of lutein in humans, J Nutr, 1999:129(2):349-55.

27. Van het Hof $K H$, Brouwer IA, West $C E$, et al., Bioavailability of lutein from vegetables is 5 times higher than that of betacarotene, Am I Clin Nutr, 1999;70(2):261-8.

28. Breithaupt $D E$, Bamedi $A$, Wirt $U$, Carotenol fatty acid esters: easy substrates for digestive enzymes? Comp Biochem Physiol B Biochem Mol Biol, 2002;132(4):721-8.

29. Granado-Lorencio F, Herrero-Barbudo C, Olmedilla-Alonso B, et al., Lutein bioavailability from lutein ester-fortified fermented milk: in vivo and in vitro study, I Nutr Biochem, 2010;21(2):133-9.

30. Bowen PE, Herbst-Espinosa SM, Hussain EA, StacewiczSapuntzakis M, Esterification does not impair lutein bioavailability in humans, J Nutr, 2002:132(12):3668-73.

31. Norkus EP, Norkus KL, Dharmarajan TS, et al., Serum lutein response is greater from free lutein than from esterified lutein during 4 weeks of supplementation in healthy adults, I Am Coll Nutr, 2010;29(6):575-85.

32. Norkus EP, Bioavailability of free lutein in comparison with lutein esters. Presented at: Lutein and its Benefits in Eye Health, Schloss Hohenkammer, Germany, 23 March 2011.

33. Schalch W, Beck M, Roos F, et al., Lutein bioavailability is matrix-dependent in powdered dietary supplements, Acta Ophthalmologica 2010;88:0. Special Issue: Abstracts Acta from the 2010 European Association for Vision and Eye
fer Research Conference.

34. WHO, Safety evaluation of certain food additives. Prepared by the sixtythird meeting of the Joint FAO/WHO Expert Committee on Food Additives (JEFCA), WHO Food Additives Series 54, Geneva: WHO, 2006. Available at: http://whqlibdoc.who.int /publications/2006/9241660546_eng.pdf (accessed 20 September 2011).

35. EFSA (European Food Safety Authority) Panel on Food Additives and Nutrient Sources added to Food (ANS), Scientific Opinion on the re-evaluation of lutein (E 161b) as a food additive, EFSA Journal, 2010;8(7):1678. 